\title{
Sociedade inclusiva: \\ a face aparente do capitalismo em uma nova fase
}

Leonardo Docena Pina

Mestre em Educação pela Universidade Federal de Juiz de Fora

\section{Resumo}

A partir das formulações de Gramsci sobre ideologia, intelectuais e hegemonia, este trabalho realiza um debate teórico com intelectuais que defendem a inclusão social e a sociedade inclusiva. O texto aborda limitações da inclusão social e situa a difusão desse paradigma como um procedimento que reforça a hegemonia burguesa.

Palavras-chave: Exclusão; Inclusão social; Sociedade inclusiva.

\begin{abstract}
On the basis of the concept of Gramsci about ideology, intellectuals and hegemony, this work make a theoretical debate about social inclusion and the inclusive society. The text explain limitations of the social inclusion and explain that the diffusion of this paradigm is a procedure that strengthens hegemony of the block on the power.
\end{abstract}

Keywords: Exclusion; Social Inclusion; Inclusive society. 
$\mathrm{O}$ presente texto se insere nos esforços que venho realizando para analisar a ideologia da inclusão social, assim como sua relação com a hegemonia do bloco no poder ${ }^{1}$. A contribuição específica deste texto centra-se na análise de uma tese que vem ganhando espaço atualmente. Trata-se da ideia de que "o paradigma da inclusão vincula-se à transformação social, mas ações vinculadas ao neoliberalismo têm 'distorcido' a inclusão para alinhá-la à conservação do capitalismo"2. A difusão dessa ideia contribui para manter como lacuna o vínculo da inclusão social com a reprodução ideológica do capitalismo. Para analisar a tese em questão, o texto faz uso de formulações de Gramsci sobre hegemonia, intelectuais e ideologia, buscando aprofundar o debate contemporâneo sobre inclusão social.

\section{Exclusão social: o ponto de partida da inclusão}

Marques (2001) demonstra que os indivíduos portadores de deficiência e condutas típicas compõem uma categoria colocada à margem do processo social. Dentre os aspectos abordados pelo autor que evidenciam a problemática em questão, encontra-se a temática da normalidade/anormalidade. Suas reflexões evidenciam que a segregação das pessoas com deficiência e condutas típicas em instituições especializadas, assim como a segregação de outros grupos desviantes, constituiu um processo perverso, que se assenta na "criação da figura do anormal". O autor explica que, a partir da criação de um padrão de normalidade, os desviantes desse padrão passaram a ser considerados anormais. Em virtude disso, os indivíduos com deficiência, assim como outros casos de desvio do

1 Ideologia é entendida neste texto como uma consciência social ancorada nas condições materiais da sociedade que, orientada para a prática, empurra os seres humanos para ação. Hegemonia é entendida como uma relação de poder que expressa, na sociedade capitalista, a dominação de uma ou mais frações de classe sobre o conjunto de sua própria classe e das classes antagônicas, em que o econômico e o político expressam a "direção moral e intelectual" a ser seguida pelo conjunto da sociedade (GRAMSCI, 2007).

2 Essa tese foi defendida no artigo de Landim e Ferreira Junior (2003) - um dos trabalhos que compuseram a fonte de análise da minha pesquisa de Mestrado, na qual analisei a produção teórica da educação física sobre inclusão social. 
padrão de normalidade, foram sendo segregados em instituições especializadas. No interior dessas instituições, vários grupos sociais mantinham-se à margem do convívio com as pessoas consideradas normais, configurando o que se convencionou denominar de paradigma da exclusão (MARQUES, 2001).

Durante muito tempo, o isolamento das pessoas consideradas anormais apareceu como algo benéfico aos desviantes, sobretudo devido a difusão do discurso de que as instituições especializadas serviam para proteger, educar, reabilitar ou integrar, na sociedade, cada grupo desviante. A compreensão de que as instituições especializadas, dentre elas a escola especial, assumiam a função de distanciar os desviantes do convívio social só ganhou força nas últimas décadas, sobretudo a partir da difusão dos estudos de Michel Foucault.

Esse autor entendia a exclusão como efeito de micropoderes invisíveis e capilares que não emanam das relações sociais de produção (FOUCAULT, 1999). Conforme explica Pina (2009), essa forma de compreender a exclusão não considera que a classe dominante, para manter sua hegemonia, precisa criar uma unidade, difundindo, por todo o tecido social, as ideias e comportamentos capazes de organizar e direcionar o conjunto da sociedade. Além de considerar que a exclusão social de grupos historicamente discriminados não decorre das relações de hegemonia, as formulações de Foucault sobre o tema ainda estão atreladas a outra ideia problemática. Trata-se do entendimento de que a segregação em instituições especializadas corresponde a uma exclusão do sistema enquanto tal, ou seja, é como se tal segregação empurrasse algumas pessoas "para fora" da sociedade, das relações sociais.

Segundo Fontes (2005), o fato de grandes parcelas da população terem ficado nas margens do processo de assalariamento durante longos períodos não significa que tenham permanecido fora das relações capitalistas, já que para caracterizar algum grupo social como permanecendo "fora do mercado" seria necessário que ele fosse capaz de garantir sua subsistência de modo independente das formas mercantis ou 
recorrendo a elas apenas de maneira acessória. Seguindo essa mesma lógica, pode-se compreender a segregação de grupos historicamente discriminados não mais como uma exclusão, visto que os grupos em tese "excluídos" ainda se encontram no interior das relações sociais capitalistas. A afirmação de que grupos sociais foram excluídos, mantidos totalmente de fora, desconsidera que, independentemente da forma pela qual as populações ou grupos sociais se conectam às relações sociais capitalistas, todos fazem parte dessas relações, sendo de alguma forma afetados por elas. Inúmeros acontecimentos, fatos, fenômenos que, à primeira vista, parecem absolutamente independentes, formam, na verdade, um sistema cuja coesão é garantida pelo princípio do capital, que submete todos e cada elemento da vida social à sua lógica (OLIVEIRA, 2004). A partir dessa submissão à intenção e objetivação do contínuo acúmulo de capital, inúmeros grupos sociais são obrigados a se adequar ao modo de vida exigido pelo bloco no poder. Dentre tais formas de enquadramento, encontra-se a segregação dos indivíduos considerados anormais, que se configura como uma "exclusão interna" (FONTES, 2005) e não como uma exclusão do sistema enquanto tal.

Conforme defende Mészáros (2002), o sistema do capital constituiuse, no curso da história, como uma poderosa estrutura totalizadora de controle à qual tudo deve se ajustar, inclusive os seres humanos. $\mathrm{O}$ autor explica que, para funcionar como modo totalizador de controle sociometabólico, o sistema do capital forma uma estrutura de comando adequada para exercer suas funções. Consequentemente, para atingir os objetivos metabólicos adotados, tudo deve se sujeitar às exigências do modo de controle do capital, cabendo, inclusive, a cada ser humano, provar sua “viabilidade produtiva" (MÉSZÁROS, 2002). Em relação à criação da figura do anormal, pode-se dizer que, ao não provarem sua "viabilidade produtiva" ao capital, as pessoas com deficiência foram obrigadas a se inserir em situações determinadas pela posição política e econômica 
ocupada nas relações de poder. Dentre as determinações da sociabilidade ${ }^{3}$ capitalista daquele contexto, encontrava-se o entendimento da deficiência como anormalidade, além da segregação de seus portadores, visto que os indivíduos pertencentes a esse grupo social foram tidos como um risco ao acúmulo de capital.

Segundo Platt (2004), a anormalização dos seres humanos é um processo desencadeado a partir do momento em que, para o corpo social, o indivíduo apresenta suas particularidades e estas vão se traduzindo como dados justificados ou não para sua não-pertença ao grupo social. Segundo a autora, o entendimento dessa não-pertença significa precisar quais laços coadunam para o agregamento das pessoas. Esses laços são definidos, em última instância, pelo modo de produção da existência humana, uma vez que adequação social ou normalidade e anormalidade são conceitos construídos de forma atrelada ao processo de produção e às relações sociais desencadeadas por este (PLATT, 2004). Portanto, enquanto impera a relação social que sustenta o modo de produção capitalista, o que vem a ser considerado normal em uma dada época, pode não ser considerado em outra, unicamente pela intenção e objetivação do contínuo acúmulo de capital (PLATT, 2004). Como o binômio normalidade/anormalidade resulta de um consenso social concebido diante de um padrão intencionalmente formatado pelo processo das relações sociais capitalistas (PLATT, 2004), a caracterização da deficiência como anormalidade pode ser entendida como manifestação de um procedimento que visou enquadrar esse grupo social na nova disciplina exigida para a dominação capitalista.

A partir do momento em que a deficiência passou a significar, sob o ponto de vista do bloco dominante, um risco à objetivação e ao contínuo de acúmulo de capital, foram sendo construídas estratégias para gerir esse risco, sendo a própria formulação do que é o anormal uma delas. Ao compreender que as pessoas com deficiência significavam um risco, o bloco

3 Segundo Martins (2009) "padrão de sociabilidade" refere-se à forma pela qual os indivíduos e as classes produzem e reproduzem, em um dado momento histórico, as condições objetivas e subjetivas de sua própria existência. Tais condições resultam das relações de poder e são mediadas pelas relações sociais de produção da vida humana. 
no poder buscou mantê-las à margem do convívio social. Entretanto, não bastava apenas segregá-las, era preciso convencer toda a sociedade quanto à legitimidade desse seu interesse específico. No intuito de convencer a todos que a segregação era benéfica aos indivíduos com deficiência, intelectuais orgânicos da classe dominante formularam e difundiram a ideia de que essas pessoas eram anormais e, por isso, precisavam ser internadas em instituições especializadas. Difundidas por todo o tecido social, essas ideias foram se reproduzindo na sociedade.

Ainda que a segregação desse grupo historicamente discriminado apareça como uma questão social resultante do chamado paradigma da exclusão, é importante salientar que essa segregação corresponde a uma exclusão interna do convívio com as pessoas consideradas normais; mas, ao mesmo tempo, essa segregação corresponde à inclusão desses indivíduos na lógica exigida pelo capitalismo. Portanto, em essência, esse processo corresponde a um procedimento mais recente de inclusão forçada, que enquadrou os "desviantes" na disciplina exigida pelo capital ${ }^{4}$.

A partir desse entendimento da "exclusão", torna-se possível compreender que, para erradicar as condições de inferioridade social que atingem as pessoas com deficiência, é necessário atacar os fundamentos centrais do capitalismo, visto que o fenômeno em questão é determinado pelo modo capitalista de produção da existência humana.

\section{Sociedade inclusiva: uma nova aparência do capitalismo}

Sassaki (1999) afirma que o movimento da inclusão social começou na década de 1980 nos países desenvolvidos e, na década de 1990, tomou impulso também em outros países ${ }^{5}$. Conforme defende Sassaki (1999, p.17),

4 De acordo com Fontes (2005), "inclusão forçada" se refere aos procedimentos estabelecidos pela sociedade capitalista que geram a imposição de comportamentos, normas, condutas e valores, os quais resultam em múltiplas formas de discriminação, reclusão ou segregação em seu próprio interior.

5 Romeu Kasumi Sassaki é um importante difusor dos fundamentos da inclusão social. Graduou-se em Serviço Social no Brasil e, no exterior, estudou temas como "Inserção de Pessoas com Deficiência" (Itália/Espanha) e "Educação Inclusiva (EUA). Atuou como 
o objetivo desse movimento "é a construção de uma sociedade realmente para todas as pessoas, sob a inspiração de novos princípios”, tais como: celebração das diferenças, direito de pertencer, valorização da diversidade humana, solidariedade humanitária, igual importância das minorias e cidadania com qualidade de vida. Para construir essa nova sociedade, o paradigma da inclusão defende a superação das condições de exclusão a que estão sujeitos os indivíduos pertencentes a grupos historicamente discriminados, a exemplo das pessoas com deficiência. Tal superação seria alcançada pela inclusão social. Trata-se de um

processo pelo qual a sociedade se adapta para poder incluir, em seus sistemas sociais gerais, pessoas com necessidades especiais e, simultaneamente, estas se preparam para assumir seus papéis na sociedade. A inclusão social constitui, então, um processo bilateral no qual as pessoas, ainda excluídas, e a sociedade buscam, em parceria, equacionar problemas, decidir sobre soluções e efetivar a equiparação de oportunidades para todos (SASSAKI, 1999, p.41).

O conceito de inclusão social evidencia uma tentativa de superar a "exclusão" a partir de um processo de adaptação da sociedade para "incluir", em seus "sistemas sociais gerais", aqueles que se encontram “excluídos". Segundo defensores da inclusão, tal processo visa "adequar os sistemas sociais gerais da sociedade de tal modo que sejam eliminados os fatores que excluam certas pessoas do seu seio e mantinham afastadas aquelas que foram excluídas" (SASSAKI, 1999, p.21).

Como já foi possível entender, a exclusão decorre das relações sociais de produção da existência humana. Assim, eliminar os fatores que excluem certas pessoas implica atacar os fundamentos centrais da sociedade capitalista. Entretanto, não é isso que visa a inclusão social, pois a chamada sociedade inclusiva, fim do processo de inclusão, ainda mantém os fundamentos centrais do capitalismo. Vejamos algumas evidências disso.

consultor de inclusão social junto a: Instituto Inclusão Brasil; BGH do Brasil; Escola de Gente; Banco do Brasil; Agência de Notícias dos Direitos da Infância. Além de ministrar cursos e palestras sobre assuntos relacionados a pessoas com deficiência, esse intelectual atuou como consultor de educação inclusiva nos Estados de Goiás, Acre, Minas Gerais, Paraná e ainda produziu artigos e livros sobre o tema. 
Sassaki (1999) explica que a inclusão social vem sendo efetivada em diferentes setores sociais, tais como educação, lazer e transporte. A efetivação desse processo culminaria com a construção da "sociedade inclusiva": "Quanto mais sistemas comuns da sociedade adotarem a inclusão, mais cedo se completará a construção de uma verdadeira sociedade para todos - a sociedade inclusiva" (SASSAKI, 1999, p. 42, grifos do autor). Construída a partir da adequação dos espaços sociais e de uma mudança de mentalidade, a sociedade inclusiva significaria a consolidação de um novo tipo de sociedade, alcançada através do desenvolvimento do processo de inclusão social:

a inclusão, portanto, é um processo que contribui para a construção de um novo tipo de sociedade através de transformações pequenas e grandes, nos ambientes físicos (espaços internos e externos, equipamentos, aparelhos e utensílios, mobiliário e meios de transporte) e na mentalidade de todas as pessoas, portanto, também do próprio portador de necessidades especiais (SASSAKI, 1999, p.42).

Ao contrário do que afirma Sassaki, a "sociedade inclusiva" não consiste em um novo tipo de sociedade, visto que o processo de inclusão não altera a essência do capitalismo. A inclusão social não visa construir uma sociedade totalmente nova, que possa ser chamada de "sociedade inclusiva". Trata-se apenas de uma nova face dada à velha ordem social capitalista, qual seja, a de um capitalismo menos selvagem, humanizado.

Um dos princípios centrais que sustentam o capitalismo diz respeito à produção de mercadorias. Tudo no interior desse modo de produção da existência humana tende a se transformar em mercadoria, inclusive a força de trabalho. Em virtude disso, um pressuposto do capitalismo é a dissociação entre trabalhadores e a propriedade dos meios pelos quais realizam o trabalho (MARX, 2008). Essa dissociação formou duas espécies diferentes de possuidores de mercadoria: de um lado, o proprietário de dinheiro, de meios de produção e de meios de subsistência, interessado em produzir capital; de outro lado, o trabalhador, detentor apenas de sua força de trabalho, que a vende como condição para manter sua existência. 
Uma evidência de que a inclusão social não visa alterar os fundamentos centrais do modo de produção vigente reside no fato de que tal paradigma não visa erradicar esse princípio central do capitalismo. Ao invés de atacar os fatores que levam os trabalhadores a venderem sua força de trabalho ao capital, o paradigma da inclusão se limita à luta pela "inclusão" no mercado de trabalho. Seguindo a tendência de entender que o "problema dos dias de hoje" não é a exploração, mas a "exclusão", o processo de inclusão social não se propõe a superar as leis do mercado, mas, apenas, modificá-las, para que pessoas pertencentes a grupos discriminados tenham maiores oportunidades de vender sua força de trabalho. Sob a ótica de Sassaki (1999, p. 60),

O mercado de trabalho, no passado, pode ser comparado a um campo de batalha: de um lado, as pessoas com deficiência e seus aliados empenhando-se arduamente para conseguir alguns empregos; e de outro, os empregadores, praticamente despreparados e desinformados sobre a questão da deficiência, recebendo ataques furiosos por não preencherem as vagas com candidatos portadores de deficiência tão qualificados quanto os candidatos não-deficientes.

O "no passado" a que se refere o autor consiste na chamada "fase da exclusão", na qual "a pessoa com deficiência não tinha nenhum acesso ao mercado de trabalho competitivo" (SASSAKI, 1999, p.60). Trata-se da fase em que "a humanidade considerava uma crueldade a idéia de que pessoas deficientes trabalhassem", visto que "empregar pessoas deficientes era tido como uma forma de exploração que deveria ser condenada por lei" (SASSAKI, 1999, p.60). Sob o ponto de vista desse intelectual, os dias de hoje devem configurar uma fase na qual as pessoas com deficiência sejam "inseridas no mercado de trabalho". Vale ressaltar que, para ele, o mercado de trabalho não deve ser constituído pelo antagonismo entre as classes sociais, pois, em seu entendimento, trabalhadores e capitalistas deveriam enfrentar juntos os desafios da produtividade e competitividade. Dessa forma, se, na "fase da exclusão", o mercado de trabalho poderia ser comparado a um campo de batalha, composto, de um lado, pelos capitalistas e, de outro, pelos trabalhadores (sejam eles deficientes ou não deficientes), 
na atual fase da inclusão, o mundo do trabalho tende a não ter dois lados. Agora, os protagonistas, em geral, parecem querer enfrentar juntos o desafio da produtividade e competitividade. A idéia que começou a vingar timidamente é a de que não haverá mais batalhas e muito menos vencedores e vencidos. Surge, então, no panorama do mercado de trabalho a figura da empresa inclusiva (SASSAKI, 1999, p.65).

Para Sassaki (1999, p.65), empresa inclusiva é "aquela que acredita no valor da diversidade humana, contempla as diferenças individuais, efetua mudanças fundamentais nas práticas administrativas, implementa adaptações nos ambientes físicos, adapta procedimentos e instrumentos de trabalho, treina todos os recursos humanos na questão da inclusão".

Aparentemente, a "empresa inclusiva" pode significar um avanço por ampliar as possibilidades das pessoas com deficiência garantirem sua sobrevivência, a partir da venda de sua força de trabalho. Da mesma forma, pode-se considerar um avanço o reconhecimento da pessoa com deficiência como indivíduo possuidor de capacidades laborativas. Entretanto, tais avanços se deram de modo a representar vantagem para o capital. Nenhuma das modificações propostas pela empresa inclusiva visa alterar a essência das relações sociais capitalistas. Assim, a absorção efetiva de todos os deficientes no mercado de trabalho é impedida, pois a própria dinâmica capitalista implica a formação de um exército de reserva, que empurra grande parte dos trabalhadores para as margens do mercado. Para agravar essa tendência, o sentido de superfluidade (ANTUNES, 2005) do capitalismo contemporâneo ainda tem ampliado a "exclusão" dos trabalhadores - deficientes ou não. Se, por um lado, a manutenção do capitalismo determina a esterilidade dos esforços direcionados à absorção das pessoas com deficiência pelo mercado de trabalho, fazendo-as engrossar o exército de reserva junto aos outros “excluídos” (LANCILLOTTI, 2003); por outro lado, isso não significa que a efetivação do processo de inclusão não permita a compra da força de trabalho de alguns desses indivíduos, já que o capitalismo não se importa com quem ele está explorando.

$\mathrm{O}$ avanço tecnológico que introduziu a acumulação flexível foi utilizado para maximizar a exploração da força de trabalho, ampliando os 
índices de desemprego. Porém, para alguns intelectuais, esses efeitos gerados pela dinâmica capitalista parecem não interferir no processo de inclusão social, nem devem ser motivos para os trabalhadores visualizarem os capitalistas como membros de uma classe antagônica. É que, para Sassaki (1999, p.75), a “inclusão no mercado de trabalho competitivo não é um sonho impossível de ser realizado, desde que os empregadores sejam tratados como parceiros". Com essa formulação, duas importantes implicações ideológicas da inclusão tornam-se claras. A primeira delas é fazer com que as pessoas pertencentes à classe trabalhadora acreditem na possibilidade de serem "incluídas no mercado de trabalho" por meio da inclusão social. A ideia é buscar o convencimento de que as modificações superficiais defendidas pela inclusão dão conta de "inserir" as pessoas com deficiência no mercado de trabalho. Assim, acreditando que a inclusão é um sonho possível, torna-se mais fácil impedir que essas pessoas e seus "aliados" organizem-se em torno de um projeto de sociedade que vise superar o capitalismo. Outra função ideológica evidenciada pela formulação apresentada consiste em uma tentativa de convencer as pessoas pertencentes à classe trabalhadora de que os capitalistas devem ser vistos como parceiros e não como indivíduos pertencentes a uma classe antagônica. Dessa maneira, torna-se mais fácil amenizar os conflitos de classe.

A chamada inclusão social no mercado de trabalho é apenas uma das formas pelas quais o paradigma da inclusão tem se manifestado. Já foi mencionado que o processo de inclusão busca se efetivar nos "sistemas sociais gerais da sociedade" e que a disseminação desse processo teria como objetivo a construção da chamada sociedade inclusiva. Esta, também chamada de "sociedade para todos", seria composta por sistemas sociais gerais "inclusivos", que dariam forma a um "novo tipo de sociedade". Porém, ao refletir sobre o processo de inclusão no mercado de trabalho, torna-se possível compreender que a inclusão social não visa construir um novo tipo sociedade. Evidência disso é o fato de que a chamada empresa inclusiva, que aparentemente se manifesta como algo que valoriza a diversidade humana, mantém a mesma essência da "empresa comum": visa 
explorar os seres humanos. Isso evidencia que a inclusão social não busca construir um novo tipo de sociedade, essencialmente diferente do capitalismo, mas, sim, promover alterações que mantenham a natureza das relações sociais vigentes.

Ainda que a inclusão social seja um processo que traz alterações na sociedade, essas alterações não mudam a essência do capitalismo. Por isso, é uma atitude idealista denominar de "sociedade inclusiva" um modo de produzir a vida essencialmente regulado pelo capital. A assim chamada "sociedade inclusiva" não passa, pois, de uma forma aparente da sociedade capitalista em uma nova fase.

\section{Sobre a suposta distorção do paradigma da inclusão social}

Nesta seção, pretende-se analisar a tese - defendida por Landim e Ferreira Júnior (2003) - de que o paradigma da inclusão vincula-se à transformação social, mas ações vinculadas ao neoliberalismo têm “distorcido" a inclusão para alinhá-la à conservação do capitalismo. Essa ideia defendida pelos autores se contrapõe à tese defendida por Pina (2009) e Lancillotti (2003), os quais, de diferentes formas, relacionam a inclusão social à manutenção da sociedade capitalista.

Landim e Ferreira Júnior (2003) reconhecem que, desde a crise da década de 1970, o capitalismo vem passando por uma restruturação política, econômica, além de uma reorganização da produção ${ }^{6}$. Os autores também reconhecem a interferência dessa reestruturação capitalista na educação, pois afirmam que a adoção das políticas neoliberais delineou reformas educacionais na América Latina a partir de $1990^{7}$.

6 Os autores não mencionam que essa recomposição capitalista significou também uma mudança no modo de vida, que instaurou o pós-modernismo como lógica cultural da atual etapa capitalista.

7 Uma análise da relação entre o neoliberalismo e a implantação de políticas educacionais na América Latina e no Caribe na década de 1990 foi realizada por Melo (2003). A autora comprova que o programa de Educação para Todos, implantado em nosso país durante o período mencionado, constitui-se como o projeto neoliberal de sociedade e de educação. Sobre a influência do projeto neoliberal de sociedade e educação na delimitação das políticas de educação especial no Brasil, pode-se recorrer ao estudo de Romero (2006). 
Landim e Ferreira Júnior (2003) explicam que, sob a égide do Banco Mundial e objetivando um deslocamento da ideologia do desenvolvimento para a ideologia da globalização, a educação escolar tem sido inscrita nas políticas de alívio da pobreza com a função ideológica de admitir a possibilidade de inclusão social através de políticas neoliberais. No seu entendimento, essas políticas de alívio da pobreza enquadram-se em uma perspectiva de "transformação cultural" que promove a distorção de princípios e conceitos ligados a ideais contra hegemônicos, de modo a reinterpretá-los a serviço da manutenção do capitalismo. É nesse contexto de reformas que estariam situadas as apropriações neoliberais da inclusão:

Neste mesmo contexto de reformas, pode-se observar a defesa do paradigma da inclusão por diversos sujeitos e diferentes facções da sociedade, aparecendo em diversos documentos oficiais, servindo inclusive como base para argumentação de algumas política sociais. No entanto, temos que reconhecer que: se de um lado esta defesa tem sido feita por teóricos e educadores realmente comprometidos com a transformação educacional e social; por outro esta tem sido apropriada, apenas à nível do discurso, como justificativa de algumas políticas "ditas inclusivas" que tem implementado ações com o intuito de mascarar certos problemas sociais (LANDIM e FERREIRA JÚNIOR, 2003, p. 4).

Os autores reconhecem que a inclusão vem sendo utilizada para mascarar as contradições do capitalismo, mas, para eles, se trata de uma distorção dos fundamentos centrais desse paradigma. Isso pode ser evidenciado pelo apontamento de que a defesa da inclusão tem sido apropriada apenas ao nível do discurso como justificativa para implementar ações que visam mascarar problemas sociais. Embora não acreditem que os fundamentos essenciais da inclusão estejam relacionados à implicação ideológica de "mascarar" os problemas do capitalismo, os autores conseguem captar o porquê do distanciamento entre as propostas educacionais da inclusão e sua efetivação na prática. Conforme explicam, "as atuais políticas educacionais, apesar de discursar muito em favor da inclusão, não tem demonstrado real ataque ao processo que vem produzindo sua necessidade: a exclusão social” (LANDIM e FERREIRA JÚNIOR, 
2003, p. 4). Esses intelectuais compreendem o vínculo entre os documentos oficiais da educação e a atual recomposição capitalista, o que lhes permite visualizar que tais documentos não visam efetivar a inclusão. Tal compreensão lhes permite captar que o distanciamento entre a prática e o que preconiza a política de inclusão escolar decorre da ausência de um compromisso real com a inclusão:

Embora possamos evidenciar alguns avanços nos documentos que legislam e orientam a educação, percebemos que na prática isso não tem ocorrido, devido a falta de uma política educacional que realmente esteja comprometida com a efetivação de uma educação inclusiva. Portanto, é preciso que os educadores estejam conscientes de modo a explorar as lacunas $\mathrm{e}$ ambigüidades presentes nas leis e se organizem a fim de exigir os meios e recursos necessários para construção de um sistema educacional que valorize a diversidade humana (LANDIM e FERREIRA JÚNIOR, 2003, p. 4).

Os autores não conseguem compreender que os objetivos proclamados pelas formulações sobre educação inclusiva dificilmente podem ser alcançados no interior da sociedade capitalista.

No capitalismo, a divisão da sociedade em classes e a consequente necessidade de apropriação privada do saber pela classe dominante têm contribuído para a não expansão de escolas públicas com consistente padrão de qualidade para toda a população. Conforme explica Saviani (2005b), o saber produzido socialmente é uma força produtiva, é um meio de produção, e como a sociedade capitalista funda-se na apropriação privada dos meios de produção, a tendência é fazer do saber uma propriedade exclusiva da classe dominante. $\mathrm{O}$ autor explica que essa tendência não pode ser levada às últimas consequências, pois isso entraria em contradição com os próprios interesses do capital, visto que o trabalhador necessita de algum conhecimento para poder produzir mercadorias. Daí a necessidade da classe dominante oferecer o acesso ao saber à classe trabalhadora em "doses homeopáticas". Nas palavras de Saviani (2005b, p.99):

Conforme se acirra a contradição entre a apropriação privada dos meios de produção e a socialização do trabalho realizada pela própria sociedade capitalista, o 
desenvolvimento das forças produtivas passa a exigir a socialização dos meios de produção, o que implica a superação da sociedade capitalista. Com efeito, socializar os meios de produção significa instaurar uma sociedade socialista, com a conseqüente superação da divisão em classes. Ora, considerando-se que o saber, que é objeto específico do trabalho escolar, é um meio de produção, ele também é atravessado por essa contradição. Conseqüientemente, a expansão da oferta de escolas consistentes que atendam a toda a população significa que o saber deixa de ser propriedade privada para ser socializado. Tal fenômeno entra em contradição com os interesses atualmente dominantes. Daí a tendência a secundarizar a escola, esvaziando-a de sua função específica, que se liga à socialização do saber elaborado, convertendo-a numa agência de assistência social, destinada a atenuar as contradições da sociedade capitalista.

Com base nessas reflexões, pode-se afirmar que concretizar uma educação de qualidade para todos significa efetivar uma educação que forneça a todos o acesso ao saber sistematizado, isto é, que socialize os bens intelectuais. Como na sociedade capitalista o acesso ao saber sistematizado tende a ser apropriado e controlado pela classe dominante, a escola inclusiva não é capaz de oferecer uma educação de alta qualidade para todos os indivíduos. Embora seja importante defender o fim da segregação em escolas especiais, é necessário reconhecer que a educação inclusiva é insuficiente nos marcos do capitalismo, visto que, nesse modo de produção da existência humana, impera a apropriação privada do saber sistematizado. Em virtude do dualismo de classe na educação brasileira, uma pessoa com deficiência que tem acesso a escolas privadas com consistente padrão de qualidade estará em condições muito vantajosas em comparação com aqueles que, na miséria, sofrem os devastadores efeitos do capitalismo. Assim, à defesa pela inserção das pessoas com deficiência e condutas típicas nas escolas regulares deve-se acrescentar a defesa pela escola pública de qualidade.

Saviani (2005a) explica que a luta pela escola pública de qualidade coincide com a luta pela superação do capitalismo:

na sua radicalidade, o desafio posto pela sociedade de classes do tipo capitalista à educação pública só poderá 
ser enfrentado em sentido próprio, isto é, radicalmente, com a superação dessa forma de sociedade. A luta pela escola pública coincide, portanto, com a luta pelo socialismo, por ser este uma forma de produção que socializa os meios de produção superando sua apropriação privada. Com isso, socializa-se o saber viabilizando sua apropriação pelos trabalhadores, isto é, pelo conjunto da população (SAVIANI, 2005a, p. 257).

Landim e Ferreira Júnior (2003, p.1) salientam que uma das finalidades de seu estudo é "resgatar a radicalidade teórica do paradigma inclusivo e reafirmar a valorização da diversidade humana como princípio central". Eles explicam que, para atingir esse intuito,

serão resgatados os pontos centrais do paradigma inclusivo, enquanto perspectiva de transformação social, que precisam ser confirmados e reafirmados, a fim de evitar os equívocos e armadilhas evidenciadas em documentos oficiais ao tratar da inclusão no sistema escolar (LANDIM e FERREIRA JÚNIOR, 2003, p.1).

Esse trecho reforça o entendimento dos autores de que documentos oficiais estariam tratando de "outra inclusão", que, distorcida, estaria atrelada aos interesses dominantes.

Landim e Ferreira Júnior (2003, p.1) afirmam que as "pessoas com algum tipo de deficiência ou comportamento desviante sempre foram vistas como um 'apêndice' da sociedade" e que as formas como elas têm sido tratadas conservam, em seu cerne, um olhar estigmatizador, discriminatório e "excludente", que empurra essas pessoas para as "margens das relações sociais". Vale salientar que esse processo que empurra as "pessoas desviantes" para as margens das relações sociais é um procedimento de inclusão forçada (FONTES, 2005) para enquadrar os indivíduos na disciplina exigida pelo capital. Ao não compreender que essas condições resultam de procedimentos de inclusão forçada, torna-se mais fácil assimilar o entendimento de que tais condições podem ser superadas sem atacar a essência do capitalismo. Os autores mencionam que, para superar as condições sociais a que estavam sendo submetidas as pessoas desviantes, surgiu, em meados do final da década de 1960, "um movimento de integração social que de acordo com Sassaki (1997), buscava a inserção das 
pessoas deficientes em todas as instâncias sociais, como a Educação, o trabalho, a família e o lazer" (LANDIM e FERREIRA JÚNIOR, 2003, p.2). Com o fracasso desse movimento,

surge no final da década de 80 e início da década de 90 um novo movimento que prega a incapacidade da integração de propiciar a plena participação de todos na sociedade. O novo movimento é fundamentado nos ideais de uma sociedade inclusiva e defende a valorização da diversidade humana para além da questão da deficiência. Configurando-se assim, não apenas como perspectiva de Educação para deficientes, mas como um novo paradigma educacional (LANDIM e FERREIRA JÚNIOR, 2003, p.2).

Como afirmam os intelectuais, o novo movimento defende a "valorização da diversidade humana" para além da deficiência e fundamenta-se nos ideais de uma "sociedade inclusiva". Nesse ponto, é importante salientar que o "novo movimento" mencionado pelos autores é o chamado paradigma da inclusão.

Proclamando a "valorização da diversidade", a ideologia da inclusão social tem seduzido inúmeros grupos discriminados, dentre os quais se encontram as pessoas com deficiência. A consequência disso é a concentração de grupos sociais em torno de demandas e formulações que por não articularem as legítimas demandas plurais com um projeto contrahegemônico - acabam promovendo a fragmentação da política e sua dissociação com a economia. A dimensão ideológica veiculada consiste na ideia de que o elemento fundamental para superar a "sociedade excludente" é a "aceitação e valorização da diversidade", sem, contudo, indicar a necessidade de promover mudanças profundas nos fundamentos culturais, sociais, políticos e econômicos do capitalismo. De fato, a construção de uma sociedade justa envolve necessariamente a valorização das diferenças. Entretanto, as diferenças humanas não podem ser efetivamente valorizadas em um modo de produção da existência que empurra para a miséria grande parte daqueles que precisam vender sua força de trabalho para sobreviver.

Embora a inclusão tenha o objetivo real de manter a sociedade que produz a "exclusão", isso tende a ser mantido como lacuna por seus 
objetivos proclamados. Como Landim e Ferreira Júnior (2003) não conseguem visualizar tal lacuna, eles se pautam na percepção de que o paradigma da inclusão se opõe à "sociedade excludente":

Contrapondo-se a visão excludente de sociedade, o novo paradigma possui como eixo central a diversidade, sua aceitação e valorização é condição fundamental para construção de uma nova concepção de homem e visão de mundo (LANDIM e FERREIRA JÚNIOR, 2003, p.2).

O paradigma da inclusão defende a adoção de novos valores morais para a vida na sociedade (capitalista), os quais estariam atrelados à construção de uma nova visão de homem, mundo e sociedade. Uma das formas de aparecimento da questão da moral no ideário da inclusão vinculase ao entendimento de que a adoção dos valores pautados na diversidade seria capaz de alterar a condição de barbárie produzida pelo capitalismo contemporâneo $^{8}$. Daí a ênfase das classes dominantes no entendimento de que a educação escolar deve fomentar valores pautados na diversidade, de modo a contribuir para a construção da sociedade inclusiva. Landim e Ferreira Júnior (2003) assimilam essa noção, pois afirmam que

A escola, enquanto espaço de contradição, deve assumir o papel de agente no processo de mudança de uma concepção excludente de sociedade para outra fundada na diversidade humana, caminhando para uma profunda mudança em toda a dinâmica educacional e social. Os reflexos desse movimento serão sentidos, principalmente, no que toca à construção de novos sentidos éticos e morais para os relacionamentos sociais (LANDIM e FERREIRA JÚNIOR, 2003, p.3).

Nessa afirmação, consta ainda o entendimento de que a construção da sociedade inclusiva significaria uma "profunda mudança" em toda a dinâmica social. Tal afirmação desconsidera que as transformações promovidas pela inclusão social são de cunho superficial, ou seja, não alteram a natureza das relações sociais vigentes.

Landim e Ferreira Júnior (2003) confundem a essência da inclusão com seu aparecer imediato e não entendem que esse paradigma está

8 A respeito da relação do paradigma da inclusão com a educação moral no contexto de crise econômica do capitalismo, conferir Pina (2009a; 2009b). 
ideologicamente atrelado à manutenção da sociedade capitalista. Os autores reconhecem o vínculo entre as políticas inclusivas e o neoliberalismo, mas, ao não compreender que a essência da inclusão é oposta à superação das relações sociais capitalistas, eles defendem que o processo de inclusão efetivado em nosso país é fruto de uma distorção que o alinhou aos interesses dominantes. Sua percepção é a de que os fundamentos essenciais do paradigma da inclusão estariam comprometidos com a transformação social:

É imprescindível uma análise cuidadosa a respeito do paradigma inclusivo, a fim de não cair nas apropriações e distorções neoliberais e de não coadunar com as políticas e ações pseudo inclusivas, contrariando assim, a própria essência da Inclusão. Deste modo, é preciso resgatar a centralidade do respeito à diversidade e o comprometimento da proposta inclusiva com a transformação social (LANDIM e FERREIRA JÚNIOR, 2003, p. 6, grifo dos autores).

A transformação social a que se referem os autores não significa a superação do capitalismo. Como vimos, a inclusão social visa construir a chamada sociedade inclusiva e, por se alinharem aos fundamentos centrais da inclusão social, os autores adotam a defesa por esse "novo tipo de sociedade":

Nossa pesquisa, tendo como foco de estudo no interior da escola a Educação Física, visa analisar de que maneira esta disciplina deve atuar a fim de garantir plena articulação entre sua prática pedagógica e os princípios de um ensino escolar comprometido com a construção de uma sociedade inclusiva (LANDIM e FERREIRA JÚNIOR, 2003, p.1).

Conforme já mencionado, Landim e Ferreira Júnior (2003) buscaram resgatar os pontos centrais do paradigma da inclusão, que estariam supostamente atrelados à transformação social. O resgate desses pontos evidenciou que a transformação social defendida por esses intelectuais vincula-se à construção da sociedade inclusiva, que nada mais é do que a aparência da sociedade capitalista em uma nova fase. Esse entendimento contrapõe-se à tese de que a inclusão social, em sua radicalidade, visa a transformação social. Foi possível compreender que as ações desse 
paradigma visam dar uma face mais humanizada para o capitalismo, proclamando a incorporação de grupos historicamente discriminados ao centro da vida social. Embora Landim e Ferreira Júnior (2003) defendam a tese de que o paradigma da inclusão foi apropriado pelo neoliberalismo, possuindo uma essência vinculada a transformação da sociedade, pode-se dizer, em conformidade com as reflexões apresentadas nesta seção, que esse paradigma vincula-se à manutenção da sociedade capitalista. Não se trata, portanto, de uma distorção dos fundamentos da inclusão social. O reordenamento capitalista que instaurou o neoliberalismo apenas resgatou os princípios centrais da inclusão social, proclamando-os como estratégia para reforçar a hegemonia do bloco no poder.

\section{Considerações finais}

A partir das reflexões de Marx e Engels (2007) e Gramsci (2000; 2001a; 2001b), torna-se possível afirmar que as ideias que circulam em uma determinada época, longe de serem autônomas, pertencem a uma determinada concepção de mundo e, portanto, tendem a influenciar o curso da história em conformidade com os interesses da classe a que se vinculam.

Marx e Engels (2007) mostram que a classe que dispõe dos meios de produção material dispõe também dos meios de produção imaterial, o que a permite controlar a produção e a distribuição das ideias de seu tempo a ponto de garantir que aquelas vinculadas à sua concepção de mundo sejam as ideias dominantes de sua época. Um aprofundamento dessa formulação de Marx e Engels é fornecido por Gramsci (2000; 2001a; 2001b). O autor indica que as ideias que compõem a ideologia da classe dominante são difundidas por todo o tecido social através do exaustivo e permanente trabalho dos intelectuais. Conforme aponta o autor, os intelectuais atuam em diferentes níveis de organização da cultura para difundi-la por todos os membros da sociedade e convertê-la em um instrumento requintado de dominação de classe (GRAMSCI, 2000; 2001a; 2001b). 
Para garantir essa dominação, cada nova classe que ocupa o lugar da que dominava anteriormente vê-se obrigada a apresentar seus interesses como sendo o interesse comum de todos os indivíduos (MARX e ENGELS, 2007), o que exige a formação ético-política dos membros da sociedade. A consolidação de tais interesses vai se ampliando à medida que a ideologia dominante vai sendo assimilada pelos indivíduos das diferentes classes sociais, estabelecendo, portanto, a hegemonia (GRAMSCI, 2000).

A partir dessas reflexões torna-se possível entender por que é tão predominante nos dias de hoje o chamado paradigma da inclusão. Como a inclusão social é uma ideologia que visa legitimar a dominação de classe (PINA, 2009), sua difusão no tecido social manifesta as próprias relações que permitem a manutenção da hegemonia da classe dominante. Em um contexto de recomposição capitalista, no qual se torna ainda mais importante para a burguesia difundir sua ideologia pela sociedade, os defensores da inclusão, analisados neste texto, desempenham um indispensável papel na reprodução ideológica do capitalismo, qual seja, o de assumir a seguinte tarefa dos intelectuais a serviço do capital: atuar de forma educativa através da difusão de formulações que negam a luta de classes.

\section{Referências bibliográficas}

ANTUNES, Ricardo. Trabalho e superfluidade. In: LOMBARDI, Claudinei; SAVIANI, Dermeval; SANFELICE, José Luís. Capitalismo, trabalho e educação. 3. ed. Campinas, São Paulo: Autores Associados, HISTEDBR, 2005.

FONTES, Virgínia. Reflexões im-pertinentes: história e capitalismo contemporâneo. Rio de Janeiro: Bom texto, 2005.

FOUCAULT, Michel. Microfísica do poder. 14. ed. Rio de Janeiro: Graal, 1999.

GRAMSCI, Antonio. Cadernos do cárcere. Volume 1. 2. ed. Rio de Janeiro: Civilização Brasileira, 2001.

GRAMSCI, Antonio. Cadernos do cárcere. Volume 2. Rio de Janeiro: Civilização Brasileira, 2000. 
GRAMSCI, Antonio. Cadernos do cárcere. Volume 3. 3. ed. Rio de Janeiro: Civilização Brasileira, 2007.

GRAMSCI, Antonio. Cadernos do cárcere. Volume 4. Rio de Janeiro: Civilização Brasileira, 2001.

LANCILLOTTI, Samira Saad Pulchério. Deficiência e Trabalho. Campinas: Autores Associados, 2003.

LANDIM, Renata Aparecida Alves; FERREIRA JÚNIOR, Gabriel Arcanjo. Resiginificações neoliberais da proposta inclusiva: repercussões para a educação e para a educação física escolar. In: CONGRESSO BRASILEIRO DE CIÊNCIAS DO ESPORTE, 13., 2003. Caxambu, Anais do Congresso Brasileiro de ciências do esporte. Caxambu, CBCE, 1 CD-ROM, GTT8.

MARQUES, Carlos Alberto. A imagem da alteridade na mídia. 2001. 248p. Tese (Doutorado em Comunicação e Cultura) - Escola de comunicação, Universidade Federal do Rio de Janeiro, Rio de Janeiro, 2001.

MARTINS, André Silva. A direita para o social: a educação da sociabilidade no Brasil contemporâneo. Juiz de Fora: Editora da UFJF, 2009.

MARX. Karl; ENGELS, Friedrich. A ideologia alemã. São Paulo: Martin Claret, 2007.

MARX, Karl. O capital. Crítica da economia política. Livro 1. Volume 2. 22. ed. Rio de Janeiro: Civilização brasileira, 2008.

MÉSZÁROS, István. Para além do capital. São Paulo/Campinas: Boitempo/Editora da UNICAMP, 2002.

MELO, Adriana Almeida Sales. A mundialização da educação. O projeto neoliberal de sociedade e de educação no Brasil e na Venezuela. 2003. 244p. Tese (Doutorado em Educação) - Faculdade de Educação, Universidade Estadual de Campinas, Campinas, 2003.

OLIVEIRA, Avelino da Rosa. Sobre o alcance teórico do conceito "exclusão". Civitas, Porto Alegre, v.4, n.1, jan/jun. 2004.

PINA, Leonardo Docena. As ilusões do paradigma da inclusão na produção teórica da educação física. 2009. 165p. Dissertação (Mestrado em Educação) - Faculdade de Educação, Universidade Federal de Juiz de Fora, Juiz de Fora, 2009.

PINA, Leonardo Docena. O paradigma da inclusão e a educação moral na sociedade capitalista em crise: repercussões na produção teórica da educação 
física. In: VI Colóquio Internacional Marx e Engels, 2009, Campinas. Anais do VI Colóquio Internacional Marx e Engels. Campinas : IFCH-Unicamp, 2009.

PLATT, Adreana Dulcina. O paradigma inclusivo das politicas educacionais e 0 paradigma excludente das políticas econômicas nos anos 90: o constructo sócioconceitual da normalidade/anormalidade (ou adequação social). 2004. 161p. Tese (Doutorado em Educação) - Faculdade de Educação, Universidade Estadual de Campinas, Campinas, 2004.

ROMERO, Ana Paula Hameriski. Análise da política pública brasileira para a educação especial na década de 1990: configuração do atendimento e atuação do terceiro setor. 2006. 220p. Dissertação (Mestrado em Educação) - Faculdade de Educação, Universidade Estadual de Maringá, Maringá, 2006.

SASSAKI, Romeu Kazumi. Inclusão. Construindo uma sociedade para todos. Rio de Janeiro: WVA, 1999.

SAVIANI, Dermeval. Educação socialista, pedagogia histórico-crítica e os desafios da sociedade de classes. IN: LOMBARDI, Claudinei; SAVIANI, Dermeval (orgs.). Marxismo e educação: debates contemporâneos. Campinas, São Paulo: Autores Associados, HISTEDBR, 2005.

SAVIANI, Dermeval. Pedagogia histórico-crítica: primeiras aproximações. 9. ed. Campinas: Autores Associados, 2005. 